\title{
Predation by jellyfish on large and emergent zooplankton: implications for benthic-pelagic coupling
}

\author{
Kylie A. Pitt ${ }^{a^{*}}$, Anne-Laure Clement ${ }^{a, b}$ \\ Rod M. Connolly ${ }^{a}$, Delphine Thibault-Botha ${ }^{b}$ \\ ${ }^{a}$ Australian Rivers Institute - Coast and Estuaries, and Griffith School of Environment, Gold Coast Campus \\ Griffith University, QLD 4222, Australia \\ ${ }^{b}$ Laboratoire d'Océanographie et de Biogéochimie, Centre d'Océanologie de Marseille, Aix-Marseille Université, Campus de Luminy, Case 901, \\ F 13288 Marseille cedex 09, France
}

Received 2 may 2007; accepted 15 August 2007

\begin{abstract}
Stable carbon isotopes were used to determine the contribution of emergent demersal zooplankton to the diet of the scyphozoan jellyfish, Catostylus mosaicus, at Smiths Lake, New South Wales, Australia. A preliminary study in 2004 indicated that there was no difference in the $\delta^{13} \mathrm{C}$ of ectodermal tissue and mesoglea of the medusae. In 2005, medusae and zooplankton present during the day and night were sampled and isotopic signatures were modelled using IsoSource. Modelling indicated that: 1) mollusc veligers and copepods sampled during the day contributed $<$ $13 \%$ of the carbon to the jellyfish, 2) copepods sampled at night contributed up to $25 \%$ and, 3) the large, emergent decapod, Lucifer, contributed $88-94 \%$. We hypothesised, therefore, that medusae derive most of their carbon from emergent species of zooplankton. In 2006, sampling done in 2005 was repeated three times over a period of 4 weeks to measure short-term temporal variation in isotopic signatures of medusae and zooplankton, and emergent demersal zooplankton was specifically sampled using emergence traps. Short-term temporal variation in isotopic signatures was observed for some taxa, however, actual variations were small $(<1.5 \%)$ and the values of medusae and zooplankton remained consistent relative to each other. IsoSource modelling revealed that mysid shrimp and emergent copepods together contributed $79-100 \%$ of the carbon to the jellyfish, and that the maximum possible contribution of daytime copepods and molluscs was only $22 \%$. Jellyfish apparently derive most of their carbon from emergent zooplankton and by capturing small numbers of relatively large taxa, such as Lucifer or mysid shrimp. Small but abundantly captured zooplankton (such as mollusc veligers) contribute only minor amounts of carbon. Jellyfish have a major role in the transfer of carbon between benthic and pelagic food webs.
\end{abstract}

\section{Introduction}

Nocturnal emergence of demersal zooplankton occurs in estuaries and coastal waters throughout the world (e.g. Alldredge and King 1980, Jacoby and Greenwood 1989, Taylor et al. 2005). Predation on emergent taxa by nocturnal pelagic predators results in a net transfer of carbon from benthic to pelagic food webs and is an important component of benthic-pelagic coupling (Kringel et al. 2003; Taylor et al. 2005).

Jellyfish are tactile predators that capture zooplankton using nematocysts. The feeding efficiency of medusae is similar during the day and night (Fancett and Jenkins 1988) and emergent zooplankton may form an important component of jellyfish diets. Although some dietary studies of jellyfish have sampled intensively during the day and night (e.g. Purcell 2003; Browne and Kingsford 2005), others have sampled during the day only (e.g. Fancett 1988; Brewer 1989; Larson 1991; Graham and Kroutil 2001) or have sampled intensively during the day but infrequently at night (Purcell 1992). Only Sullivan et al. (2001) have directly examined the contribution of emergent demersal zooplankton to the diet of gelatinous zooplankton. They found that emergent gammaridean amphipods contributed a substantial proportion of the daily carbon ration of the ctenophore, Menmiopsis leydei. 
Jellyfish are renowned for forming spectacular and episodic population blooms and there is now compelling evidence that the biomass of jellyfish has increased in many parts of the world (Brodeur et al. 1999; Link and Ford 2006; Lynam et al. 2006). Understanding the trophic ecology of medusae is important both for understanding the formation and maintenance of jellyfish blooms as well as their likely role in the transfer of carbon between benthic and pelagic food webs.

Stable isotopes are increasingly being used to elucidate trophic relationships. Isotopic analyses rely on the observation that the isotopic signature of a consumer reflects that of its prey, usually with some minor enrichment (fractionation) in the heavy isotope $\left({ }^{13} \mathrm{C}\right)$ that occurs because the consumer preferentially eliminates ${ }^{12} \mathrm{C}$ during respiration. Comparison of the isotopic signature of a consumer with its potential sources of prey, therefore, provides information about the relative contribution of different sources of prey to the diet of the consumer. The major advantages of stable isotopes over traditional gut content analyses are that they provide a time-integrated analysis of diet and are able to distinguish between what is assimilated and what is simply ingested by the consumer (Peterson and Fry 1987).

The planktivorous rhizostome, Catostylus mosaicus, frequently forms spectacular population blooms in the estuaries and coastal lagoons of eastern Australia (Pitt and Kingsford 2000). The biomass of the blooms can exceed 500 km $\mathrm{km}^{-2}$ (Pitt and Kingsford 2003) and during such times C. mosaicus is likely to be the major processor of nutrients in the estuaries. Understanding the diet of C. mosaicus is, therefore, necessary for understanding the functioning of the food webs of these systems. To date, studies of the diet of C. mosaicus have been limited to analyses of the zooplankton captured on the oral arms (Browne and Kingsford 2005; Peach and Pitt 2005). Copepods, larval crustaceans and molluscs are typically the most abundant taxa caught, but small numbers of larger zooplankton, such as Lucifer are also captured. The major objective of this study was to use stable carbon isotope analysis to further elucidate the diet of $C$. mosaicus. Specifically we aimed to:

1. compare the isotopic signatures of different types of tissues in C. mosaicus;

2. examine temporal variation in the isotopic signatures of the medusae and their potential sources of prey;

3. compare the importance of diurnal and nocturnal emergent zooplankton to the diet.

\section{Methods}

\subsection{Field collections}

The study was done at Smiths Lake, a coastal lagoon in New South Wales, Australia $\left(152.519^{\circ} \mathrm{E}\right.$, $32.393^{\circ} \mathrm{S}$ ). Smiths Lake has an area of $10.5 \mathrm{~km}^{2}$, a maximum depth of $5 \mathrm{~m}$ and its catchment is largely forested. The lake opens intermittently to the ocean but was closed at each time sampled.

Samples for isotopic analysis were collected over three years. In February 2004, three medusae were collected for a preliminary study to examine variation in isotopic signatures between the ectodermis and mesoglea of C. mosaicus. In March 2005, jellyfish and zooplankton present during the day and night were sampled. During February - March 2006 medusae, zooplankton present during the day and night, and emergent demersal zooplankton were sampled. We also incorporated measures of short-term temporal variation in 2006, by sampling 3 times over a 4 wk period, over 3 nights centred around the dates Feb 6, Feb 14 and Feb 28.

Adult jellyfish $(>150 \mathrm{~mm}$ bell diameter) were collected using a dipnet from a depth of $<1 \mathrm{~m}$. They were sampled during the day only, as their isotopic signatures would not change significantly over a period of 12 hours. Zooplankton, however, was sampled during both the day and night ( $>2 \mathrm{~h}$ after sunset) because emergent species of zooplankton may have different isotopic signatures to zooplankton that reside permanently in the water column. Zooplankton was collected using a $100 \mu \mathrm{m}$ mesh plankton net towed horizontally just below the surface for approximately $3 \mathrm{~min}$. Surface tows were used since in coastal lagoons C. mosaicus tends to occur within the top $1 \mathrm{~m}$ of the water column (Pitt and Kingsford 2003) and is likely to prey, therefore, on zooplankton occurring close to the surface. Zooplankton collected at night consisted of a combination of species that undertake nocturnal migration to surface waters and non-migratory species that reside permanently in the water column. In 2005, two jellyfish and two samples of zooplankton were collected from two sites separated by $>1 \mathrm{~km}$. To provide more information about small scale spatial and short temporal variations in isotopic signatures, on three occasions in 2006, four jellyfish and four samples of zooplankton were collected at each of three sites (i.e. a total of 36 samples each) and emergent demersal zooplankton were also sampled using four, $200 \mu \mathrm{m}$ mesh, $1 \mathrm{~m} \times 1 \mathrm{~m}$ emergence traps. Two traps were placed at each of two sites separated by $>1 \mathrm{~km}$. Individual traps rarely caught enough zooplankton to enable an isotopic signature to be obtained. To obtain sufficient quantities of material for isotopic analysis, therefore, traps were deployed for three successive nights 
and samples of zooplankton were combined from replicate traps within a site and/or across successive nights. Traps were set approximately 1 hour before sunset and cleared 30 mins after sunrise. Traps were repositioned each night to ensure different areas of substratum were sampled. All samples for isotopic analysis were frozen immediately.

\subsection{Preliminary test of tissue types}

To compare isotopic signatures between the ectodermis and mesoglea, three samples of ectodermis and mesoglea were extracted from the bell of each of three adult medusae. Comparisons were not made with tissue from the oral arms due to the potential contamination of the samples with zooplankton that had been captured by the medusae. Ectodermis was sampled by scraping thin layers from the aboral surface of the bell using a scalpel. Samples of mesoglea, free of any ectodermal or endodermal tissue, were excised from inside the bell.

The average $\delta^{13} \mathrm{C}$ of the three jellyfish used in the pilot study was $-18.4 \pm 0.17$ (SE). Differences in isotopic signatures between medusae and tissue types were analysed using a two-way ANOVA. Prior to analysis, the assumption of homogeneity of variances was tested using Cochran's test and if ANOVA identified significant differences, post-hoc Student Newman Kuels tests were used to identify where the differences occurred. Isotopic signatures varied among jellyfish $(P<0.01)$ but were consistent between the ectodermis and mesodermis $(P>0.05)$. For all subsequent analyses, therefore, we used a wedge of the bell that contained a combination of both ectodermis and mesoglea.

\subsection{Preparation and isotope analysis}

Zooplankton was separated into coarse taxonomic groups. Large taxa (e.g. the decapod Lucifer and mysid shrimp) were removed using forceps but small taxa (e.g. copepods and mollusc veligers) were separated by sieving and centrifugation. If zooplankton were not easily separated using centrifugation, colloidal silica (Ludox AM30, density =1.21) was added to increase the density gradient and assist separation. Zooplankton samples were subsequently washed to remove silica. Zooplankton and jellyfish samples were dried to constant weight at $60^{\circ} \mathrm{C}$ before being ground to a fine powder using a mortar and pestle. Zooplankton were digested in acid $(\mathrm{HCl})$ to remove carbonates and redried. Isotopic ratios were measured using an Isoprime isotope-ratio mass spectrometer, and reported as per mil values (\%) against the international standard (PeeDee belemnite limestone carbonate) using the following formula:

$$
\begin{aligned}
& \delta^{13} \mathrm{C}_{\text {sample }}=\left[\left(\mathrm{R}_{\text {sample }}-\mathrm{R}_{\text {standard }}\right) / \mathrm{R}_{\text {standard }}\right] \times 1000 \\
& \mathrm{R}={ }^{13} \mathrm{C} /{ }^{12} \mathrm{C}
\end{aligned}
$$

Precision of $\delta^{13} \mathrm{C}$ values for invertebrates analysed on the same mass spectrometer has previously been estimated at $0.2 \%$ (Connolly et al. 2005).

\subsection{Temporal variation in isotope signatures}

Temporal variations in isotopic signatures of medusae and zooplankton were analysed using ANOVAs. The number of replicates available for analyses varied between years and among sampling type (e.g. plankton tows and emergence traps). For each analysis, the number of replicates was determined by the minimum number available within a particular treatment. To ensure the analysis was balanced, therefore, replicates were randomly eliminated from treatments with excess replicates. The following comparisons were made: variation in isotopic signatures of medusae among the three times sampled in 2006 was analysed using a one-way ANOVA $(\mathrm{n}=12)$ and variation in signatures of copepods and mollusc veligers among times and between day and night was tested using two-way ANOVAs $(\mathrm{n}=12) ; \delta^{13} \mathrm{C}$ of emergent copepods and those sampled in plankton tows during the day and night were compared during the third time sampled only (i.e. when sufficient replicates from the emergent traps could be obtained) using a one-way ANOVA $(\mathrm{n}=6)$. As only two shrimp were caught during the day, analysis of shrimp was limited to emergent and night shrimp $(n=6)$. Variations in isotopic signatures between 2005 and 2006 of C. mosaicus, day and night copepods and day and night molluscs 
were compared using one-way ANOVAs ( $\mathrm{n}=4$ for all analyses). Lucifer was present in the lake only in 2005, so analysis annual variation in isotopic signatures was not possible for this taxon.

\subsection{Modelling of feasible contributions to the diet of medusae}

The $\delta^{13} \mathrm{C}$ values of jellyfishes and zooplankton were used in the IsoSource model (Phillips and Gregg 2003) to identify the contributions of zooplankton taxa to the diet of jellyfish. The IsoSource model examines all possible combinations of potential contributions of each zooplankton taxon to the diet of jellyfish (0-100\%) in small increments (here 1\%), and is used when the number of potential dietary sources is too large to permit a unique solution to the mixing equation (Phillips and Gregg 2003, Melville and Connolly 2005). Combinations that added to within $0.1 \%$ of medusae signatures were considered feasible solutions. The results of the models were reported as the distribution of feasible contributions to the diet for each zooplankton group (Phillips and Gregg 2003). Prior to modelling, the isotopic signatures of jellyfish were adjusted by $-0.5 \%$ o to correct for trophic fractionation between predators and their prey, based on the average fractionation shift for all animals (McCutchan et al. 2003). Separate IsoSource models were constructed for 2005 and 2006.

Nitrogen isotopes were not used for two reasons: 1) it has been shown recently (Connolly et al. 2005) that the larger trophic fractionation and higher uncertainty about the shift per trophic level for $\delta^{15} \mathrm{~N}$ than $\delta^{13} \mathrm{C}$ (McCutchan et al. 2003) render nitrogen unhelpful or at least riskier in feasible source modelling, and 2) important components of the zooplankton (notably emergent copepods in 2006) could not be obtained in enough quantity to analyse nitrogen isotopes (given the quantity required for acidification for carbon analysis).

In 2005 , the average $\delta^{13} \mathrm{C}$ values of four potential sources were modelled: mollusc veligers, daytime copepods, night time copepods and Lucifer sp. The average isotopic signature of molluses sampled during the day and night was used in the model because the signatures differed by less than 1\%. Lucifer sp. was captured only at night and was the only migratory species of zooplankton for which enough material was available to measure an isotopic signature. Night time copepods consisted of a combination of copepods that occurred permanently within the water column and those that migrated to surface waters at night.

Although there was statistically significant short-term temporal variation in isotopic signatures of some taxa in 2006, actual differences in $\delta^{13} \mathrm{C}$ were small. A single model was constructed, therefore, that used the average $\delta^{13} \mathrm{C}$ of jellyfish and their potential zooplankton prey, across the three times sampled. Three sources were modelled: shrimp, daytime zooplankton (i.e. the average $\delta^{13} \mathrm{C}$ of copepods and mollusc veligers) and emergent copepods. Samples of zooplankton collected at night were not used in the model because night time samples contained a combination of zooplankton that occur permanently in the water column and those that migrate into the water column at night and both these groups were already represented in the model by the day plankton and emergent copepods. The initial model indicated that the potential contributions of shrimp and emergent copepods to the diet of the jellyfish ranged widely, limiting the conclusions that could be drawn about their importance to the diet. The contributions of these zooplankton groups were therefore pooled using the procedure of Phillips et al. (2005), to sharpen estimates of the contributions of these taxa.

\section{Results}

3.1 Jellyfish and zooplankton isotope signatures

The average $\delta^{13} \mathrm{C}$ of jellyfish sampled in 2005 was -20.9 , at the enriched end of the range for prey taxa (Fig. 1). There was little separation $(<1 \%)$ of isotopic signatures of mollusc veligers sampled during the day and night, but night copepods were $2.8 \%$ more enriched than those sampled during the day. Lucifer sp., which was caught only at night and, therefore, was considered to be an emergent demersal taxon, was $>4.0 \%$ more enriched than any zooplankton sampled during the day and was $>1 \%$ more enriched than copepods sampled at night. Averaged across all times in 2006, medusae were approximately $4 \%$ more enriched than daytime copepods and molluscs and were $2 \%$ more enriched than night copepods and molluscs (Fig. 1). Emergent copepods were approximately $0.5 \%$ more depleted than medusae. Shrimp were the only zooplankton that were, on average, more enriched than medusae. 


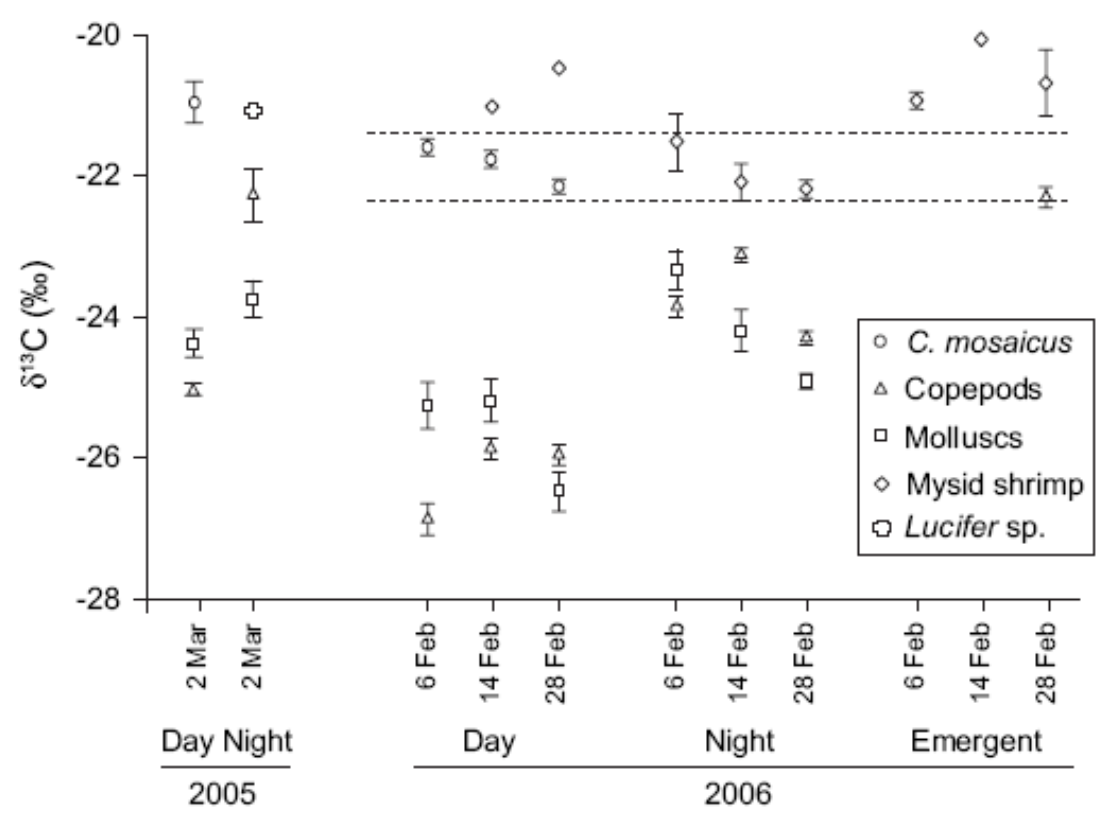

Fig. 1. Temporal variation in average $( \pm \mathrm{SE}) \delta^{13} \mathrm{C}$ values of $C$. mosaicus and its potential diurnal and nocturnal prey in 2005 and potential diumal, nocturnal and emergent prey in 2006. Dashed lines indicate the maximum and minimum range of average $\delta^{13} \mathrm{C}$ values of $C$. mosaicus sampled during 2006.

\subsection{Temporal variation in isotopic signatures in 2006}

During 2006, the $\delta^{13} \mathrm{C}$ values of the jellyfish decreased from an average of $-21.7 \%$ during the first two times sampled to $-22.2 \%$ (Fig. 1), a slight although significant difference $(P<0.05)$. There was a difference in the signatures of copepods collected during the day and night but trends were not consistent among times (Time $\mathrm{x}$ Day vs Night interaction; $P<0.05$ ). Post-hoc SNK tests revealed, however, that night copepods had consistently more enriched values than day copepods. Mollusc veligers had values about $1.5 \%$ more enriched during the night than day $(P<0.05)$. Mollusc signatures also varied among times $(P<0.01)$, being similar during the first two times sampled (average $-24.5 \%$ ) and slightly depleted at time $3(-25.7 \%$ ).

During the third time sampled, emergent copepods were more enriched in $\delta^{13} \mathrm{C}$ than night copepods $(-22.2$ $\%$ compared with $-24.2 \%$, respectively) and night copepods were more enriched than day copepods (-25.75 $\%$; Fig. 1). There was no difference in the isotopic signatures of mysid shrimp caught in emergence traps or night time plankton tows.

\subsection{Comparison of isotope signatures between 2005 \& 2006}

Isotopic signatures of molluscs sampled during both the day and night were consistent between years $(P>$ 0.05 ). Copepods sampled during the day and night were approximately $1.5 \%$ more depleted, and jellyfish approximately $1 \%$ more depleted in ${ }^{13} \mathrm{C}$, during 2006 ( $P<0.05$ for all analyses; Fig. 1$)$.

\subsection{Modelling of feasible contributions of zooplankton to the diet of jellyfish}

IsoSource modelling of 2005 values indicated that Lucifer sp. provided the majority of carbon to jellyfish (74-92\%). Night copepods contributed a maximum of $25 \%$ and mollusc veligers and daytime copepods contributed $<10 \%$ (Fig. 2).

The three-source IsoSource model constructed for 2006 indicated that daytime copepods and molluscs contributed a maximum of $21 \%$ to the diet of the medusae. The contribution of mysid shrimp and emergent copepods ranged widely from 0 to $81 \%$ (shrimp) and 1 to $97 \%$ (emergent copepods) (Fig. 3). Pooling the contributions of mysid shrimp and emergent copepods yielded a much clearer result and indicated that the 
shrimp and emergent copepods combined contributed $79-100 \%$ of the diet, while the combined contribution of day plankton was $<22 \%$ (Fig. 4).
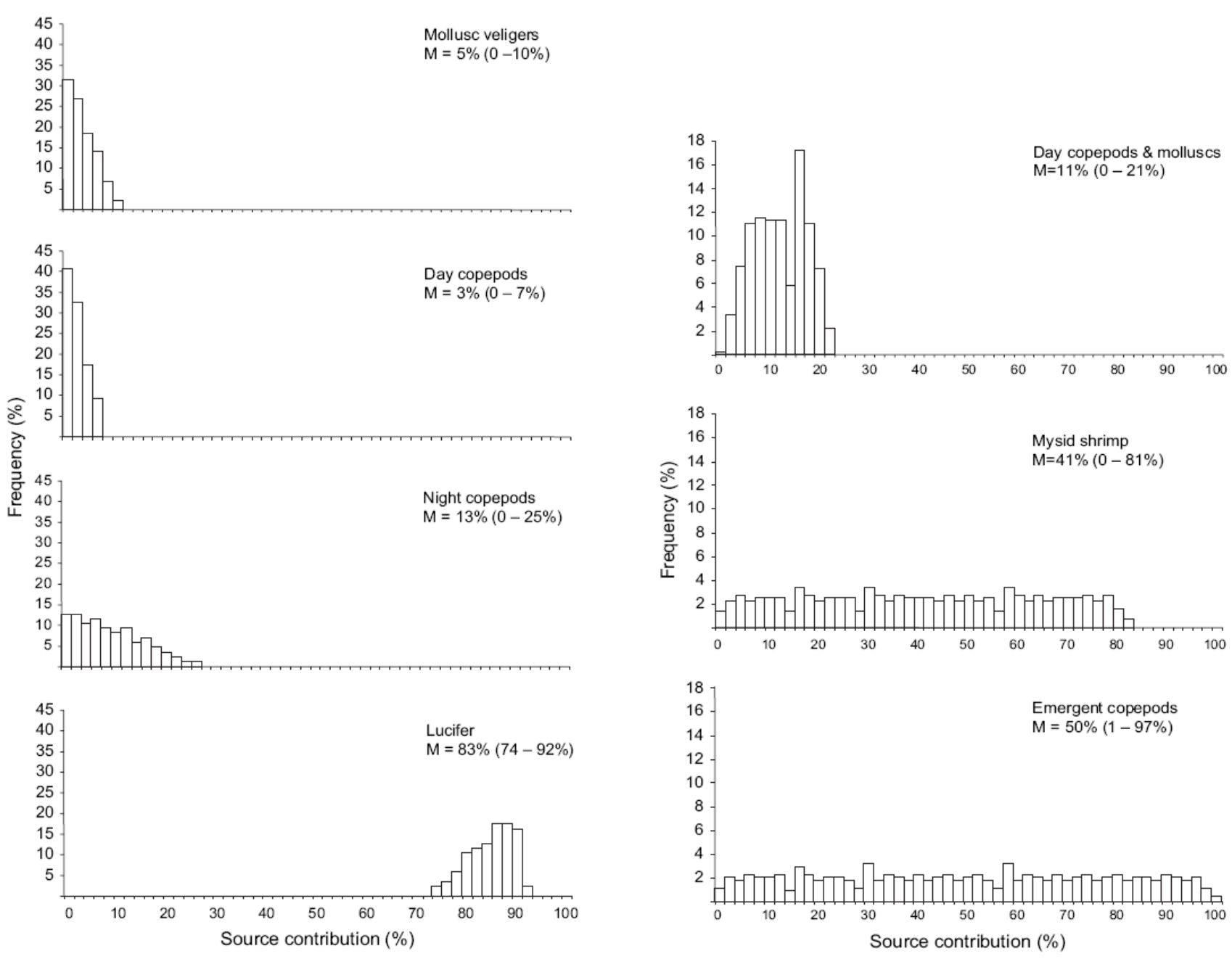

Fig. 2. Distribution of feasible contributions of available sources to C. mosaicus in 2005 , derived from IsoSource modelling. $\mathrm{M}=$ median, the ranges are 1 percentile and 99 percentile values.

Fig. 3. Distribution of feasible contributions of available sources to C. mosaicus in 2006, derived from IsoSource modelling. Median and ranges indicated as per Fig. 3.

\section{Discussion}

These results provide compelling evidence that Catostylus mosaicus derives most of its nutrition by feeding on emergent zooplankton and other relatively large taxa such as Lucifer sp. and mysid shrimp. Hypotheses regarding the importance of emergent plankton to the diet were derived from the results obtained from the modelling of the 2005 data. Modelling indicated that the decapod, Lucifer sp., contributed the most to the diet

of C. mosaicus. Lucifer sp. was considered an emergent species as it was sampled only at night and is recognised to undertake nocturnal migrations elsewhere (Oishi and Saigusa 1997). Lucifer sp. is also captured by C. mosaicus in small numbers (Browne and Kingsford 2005), suggesting that it is a feasible source of food. The modelling results of 2005, however, also provided indirect evidence that emergent copepods contributed significant amounts of carbon to the diet. Comparison of the signatures of the day and night copepods enabled

us to crudely estimate the $\delta^{13} \mathrm{C}$ of emergent copepods. The $\delta^{13} \mathrm{C}$ of the night copepods (which comprised emergent and day copepods) was greater than that of the day copepods ( $-22.3 \%$ compared to $-25.1 \%$ ). If we 
assume that the day copepods remained permanently in the water column, the $\delta^{13} \mathrm{C}$ of the emergent taxa alone, therefore, must have been greater than that of the night assemblage. When this was specifically tested in 2006,

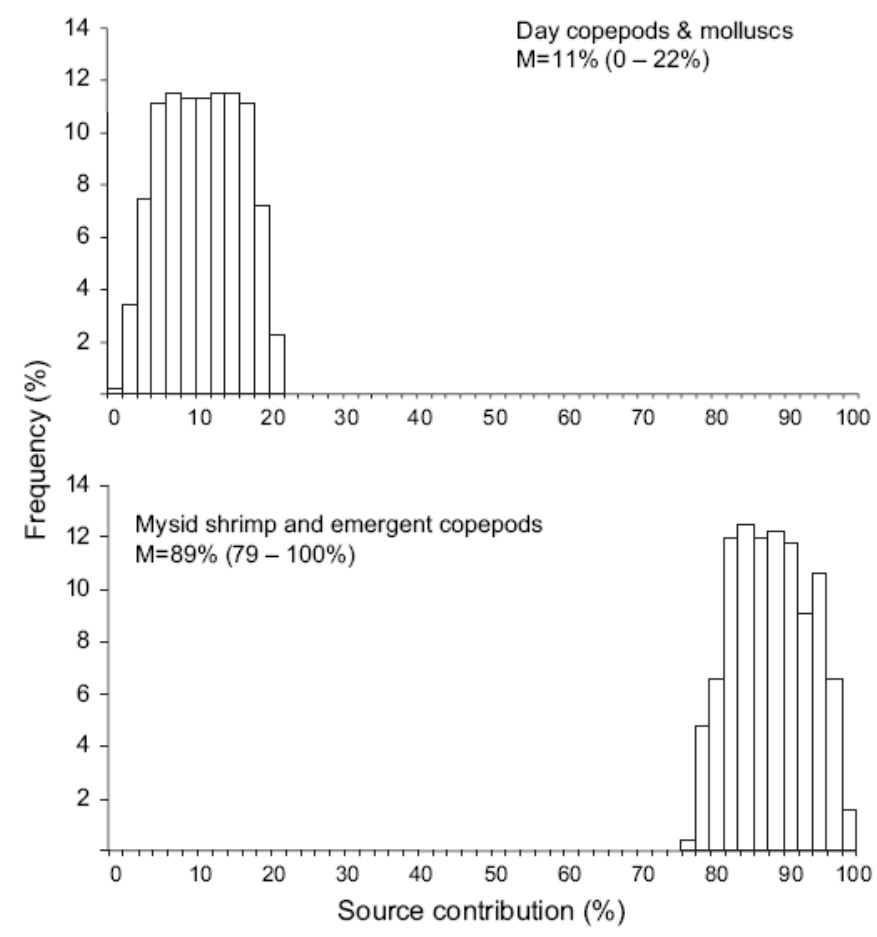

Fig. 4. Distribution of feasible contributions of available sources to C. mosaicus in 2006, following pooling of emergent copepods and mysid shrimp. Median and ranges indicated as per Fig. 3.

emergent copepods were found to be approximately $2 \%$ more enriched than the night time copepods. If this was the case in 2005, then the emergent copepods would have been even more enriched in ${ }^{13} \mathrm{C}$ than Lucifer sp., and, if modelled, would have suggested that they contribute substantial amounts of carbon to the diet of $C$. mosaicus. Based on the 2005 results we hypothesised, therefore, that C. mosaicus derived most of its carbon from capturing emergent taxa and in 2006 we made a concerted effort to sample emergent groups.

C. mosaicus and copepods were more depleted in ${ }^{13} \mathrm{C}$ during 2006 than 2005 and short-term temporal variation among times sampled within 2006 was also observed for jellyfish and some zooplankton taxa. Although statistically significant, the actual variations were generally small $(\leq 1.5 \%)$ and, importantly, the relative values of the signatures of the jellyfish and their potential zooplankton prey were consistent at each sampling time. Temporal variation in isotopic signatures has been identified as a possible factor that could limit the ability of stable isotopes to accurately identify trophic links (Syväranta et al. 2006). Although the turn over times of medusae and their prey still need to be verified using isotopic labelling, the relative stability in isotopic signatures over long ( 1 year) and short ( 4 weeks) periods in the current study suggests that isotopes were likely to provide a consistent reflection of trophic relationships.

Modelling in both 2005 and 2006 indicated that daytime copepods and molluscs contributed very little to the diet, despite these taxa being caught abundantly by C. mosaicus at Smiths Lake (Peach and Pitt 2005). Instead, relatively large decapods such as Lucifer sp. (2005) and mysid shrimp (2006) were identified as the major source of carbon. C. mosaicus has been previously observed to capture small numbers of Lucifer sp., as well as other larger crustaceans such as caridean shrimp and thalassinid larvae (Browne and Kingsford 2005). Although medusae may capture relatively few large crustaceans, larger taxa are likely to contain orders of magnitude more carbon than the more abundantly captured copepods and mollusc veligers and, therefore, may contribute a disproportionately large amount of carbon to the jellyfish. Rhizostome medusae have been shown to positively select larger zooplankton (Fancett 1988) and recently we have demonstrated, using ${ }^{13} \mathrm{C}$ labelling, that C. mosaicus can digest and assimilate $8-9 \mathrm{~mm}$ long Artemia (J. Bouchet, unpubl. data). We suggest, therefore, that C. mosaicus derives most of their carbon by feeding on small numbers of relatively large zooplankton. The importance of capturing large zooplankton appears to have been underestimated in dietary 
studies of medusae. Indeed, large zooplankton have even been deliberately excluded from calculations of elemental budgets (Båmstedt 1990; Kremer 2005), because the incorporation of large, but infrequently-captured prey has been considered to bias the budgets (Kremer 2005). Medusae can assimilate nutrients from relatively large zooplankton, and we argue that these large taxa may be a major source of nutrition for medusae.

Our results help to explain observations based on carbon budgets that populations of the semaeostome medusa, Aurelia aurita continued to grow, despite the biomass of zooplankton available being insufficient to meet their carbon demands (Båmstedt 1990; Olesen et al. 1994). The carbon budgets calculated for these studies were based on estimates of the biomass of zooplankton present only during the day. Hence the carbon contributed by emergent demersal or migratory taxa was not included in their models. Olesen et al. (1994) suggested that the discrepancy in their carbon budget may have been due to the exclusion of emergent demersal zooplankton and our data support their hypothesis. These studies concluded that populations of $A$. aurita were food limited. A demonstration of this requires, however, that the prey contributing most to the nutrition of medusae be accurately identified and included in the carbon budgets.

Modelling of the 2006 data highlighted the importance of emergent copepods as a dietary source. Emergent demersal zooplankton are typically larger than diurnal plankton (Yahel et al. 2002; Holzman and Genin 2003) and studies of nocturnal zooplanktivorous fish indicate that, although nocturnal predators consume fewer zooplankton than diurnal predators, the demersal zooplankton captured by nocturnal predators are relatively large (Holzman and Genin 2003). The overall quantity of carbon ingested by both nocturnal and diurnal zooplanktivores is, therefore, similar. In the present study nocturnal copepods were observed to be larger than diurnal copepods (A. -L. Clement; unpubl. data). We propose, therefore, that although medusae feed continuously during the day and night, they derive more carbon at night because the emergent demersal species they feed upon are larger.

The discrepancy in the $\delta^{13} \mathrm{C}$ between the emergent and diurnal copepods suggests that these two groups utilise different carbon sources. Very little information exists on the feeding habits of emergent copepods but other emergent taxa, such as mysid shrimp, feed both in the water column and on the benthos (Johansson et al. 2001). We cannot confirm the dietary source of the emergent copepods but it is, perhaps, likely that they derive nutrition from both benthic and pelagic habitats. If so, predation by jellyfish on emergent copepods represents a major translocation of carbon from benthic to pelagic food webs. Abundances of medusae fluctuate enormously (Pitt and Kingsford 2000) and data on consumption rates of emergent zooplankton are required to quantify the transfer of carbon. During times of high jellyfish abundance, however, predation by medusae on emergent zooplankton is likely to be the major mechanism by which carbon is transferred between the benthic and pelagic habitats in coastal lagoons.

\section{Conclusions}

The use of a chemical tracer in the present study produced some novel results that would not have been forthcoming using traditional gut content analyses. In particular, isotope results have indicated that the day copepods and mollusc veligers, which are caught abundantly by C. mosaicus, contribute little to their nutrition. Emergent demersal species of zooplankton contribute substantially more to the diet than zooplankton present during the day, and medusae derive most of their carbon by capturing small numbers of relatively large zooplankton. These data highlight the important role of jellyfish in benthic-pelagic coupling.

\section{Acknowledgements}

We wish to thank E. Carr, L. Manuel and E. West for assistance with fieldwork and D. Gorman, H. Moller and K. Pardoe Matthews for assistance in the laboratory. We are grateful to R. Diocares for running isotope analyses. The study was funded by a Griffith University Researcher Grant to K. Pitt and R. Connolly and a Hermon Slade Foundation Grant to K. Pitt and D. Welsh.

\section{References}

Alldredge, A.L., King, J.M., 1980. Effects of moonlight on the vertical migration patterns of demersal zooplankton. Journal of Experimental Marine Biology and Ecology 44, 133-156.

Båmstedt, U. 1990., Trophodynamics of the scyphomedusae Aurelia aurita. Predation rate in relation to abundance, size and type of prey organism. Journal of Plankton Research 12, 215-229. 
Brewer, R.H., 1989. The annual pattern of feeding, growth, and sexual reproduction in Cyanea (Cnidaria: Scyphozoa) in the Niantic River Estuary, Connecticut. Biological Bulletin 176, 272-281.

Brodeur, R.D., Mills, C.E., Overland, J.E., Walters, G.E., Schumacher, J.D. 1999. Substantial increase in gelatinous zooplankton in the Bering Sea, with possible links to climate change. Fisheries Oceanography 8 , 296-306.

Browne, J.G., Kingsford, M.J., 2005. A commensal relationship between the scyphozoan medusa Catostylus mosaicus and the copepod Paramacrochiron maximum. Marine Biology 146, 1157-1168.

Connolly, R.M., Hindell, J.S., Gorman, D., 2005. Seagrass and epiphytic algae support the nutrition of a fisheries species, Sillago schomburgkii, in adjacent intertidal habitats. Marine Ecology Progress Series 286, 69-79.

Fancett, M.S., 1988. Diet and prey selectivity of scyphomedusae from Port Phillip Bay, Australia. Marine Biology 98, 503-509.

Fancett, M.S., Jenkins, G.P., 1988. Predatory impact of scyphomedusae on ichthyoplankton and other zooplankton in Port Phillip Bay. Journal of Experimental Marine Biology and Ecology 116, 63-77.

Graham, W.M., Kroutil, R.M., 2001. Size-based prey selectivity and dietary shifts in the jellyfish, Aurelia aurita. Journal of Plankton Research 23, 67-74.

Holzman, R., Genin, A., 2003. Zooplanktivory by a nocturnal coral-reef fish: Effects of light, flow, and prey density. Limnology and Oceanography 48, 1367-1375.

Jacoby, C.A., Greenwood, J.G., 1989. Emergent zooplankton in Moreton Bay, Queensland, Australia: seasonal, lunar and diel patterns in emergence and distribution with respect to substrata. Marine Ecology Progress Series 51, 131-154.

Johannsson, O.E., Leggett, M.F., Rudstam, L.G., Servos, M.R., Mohammadian, M.A., Gal, G., Dermott, R.M., Hesslein, R.H., 2001. Diet of Mysis relicta in Lake Ontario as revealed by stable isotope and gut content analysis. Canadian Journal of Fisheries and Aquatic Sciences 58,1975-1986.

Kremer, P., 2005. Ingestion and elemental budgets for Linuche unguiculata, a scyphomedusa with zooxanthellae. Journal of the Marine Biological Association of the United Kingdom 85, 613-625.

Kringel, K., Jumars, P.A., Holliday, D.V., 2003. A shallow scattering layer: High-resolution acoustic analysis of nocturnal vertical migration from the seabed. Limnology and Oceanography 48, 1223-1234.

Larson, R.J., 1991. Diet, prey selection and daily ration of Stomolophus meleagris, a filter-feeding scyphomedusa from the NE Gulf of Mexico. Estuarine, Coastal and Shelf Science 32, 511-525.

Link, J.S., Ford, M.D., 2006. Widespread and persistent increase of Ctenophora in the continental shelf ecosystem off NE USA. Marine Ecology Progress Series 320, 153-159.

Lynam, C.P., Gibbons, M.J., Bjørn, E.A., Sparks, C.A.J., Heywood, B.G., Brierley, A.S., 2006. Jellyfish overtake fish in a heavily fished ecosystem. Current Biology 16, R492-R493.

McCutchan, J.H., Lewis, W.M., Kendall, C., McGrath, C.C., 2003. Variation in trophic shift for stable isotope ratios of carbon, nitrogen and sulfur. Oikos 102, 378-390.

Melville, A.J., Connolly, R.M., 2005. Food webs supporting fish over subtropical marine mudflats are based on transported organic matter not in situ algae. Marine Biology 148, 363-371.

Oishi, K., Saigusa, M., 1997. Nighttime emergence patterns of planktonic and benthic crustaceans in a shallow subtidal environment. Journal of Oceanography 53, 611-621.

Olesen, N.J., Frandsen, K., Riisgard, H.U., 1994. Population dynamics, growth and energetics of jellyfish Aurelia aurita in a shallow fjord. Marine Ecology Progress Series 105, 9-18.

Peach, M.B., Pitt, K.A., 2005. Morphology of the nematocysts of the medusae of two scyphozoans Catostylus mosaicus and Phyllorhiza punctata (Rhizostomeae): implications for capture of prey. Invertebrate Biology 124, 98-108.

Peterson, B.J., Fry, B., 1987. Stable isotopes in ecosystem studies. Annual Review of Ecology and Systematics 18, 293-320.

Phillips, D.L., Gregg, J.W., 2003. Source partitioning using stable isotopes: coping with too many sources. Oecologia 136, 261-269.

Phillips, D.L., Newsome, S.D., Gregg, J.W., 2005. Combining sources in stable isotope mixing models: alternative methods. Oecologia 144, 520-527.

Pitt, K.A., Kingsford, M.J., 2000. Geographic separation of stocks of the edible jellyfish Catostylus mosaicus (Rhizostomeae) in New South Wales, Australia. Marine Ecology Progress Series 136, 143-155.

Pitt, K.A., Kingsford, M.J., 2003. Temporal variation in the virgin biomass of the edible jellyfish, Catostylus mosaicus (Scyphozoa, Rhizostomeae). Fisheries Research 63, 303-313. 
Purcell, J.E., 1992. Effects of predation by the scyphomedusan Chrysaora quinquecirrha on zooplankton populations in Chesapeake Bay, USA. Marine Ecology Progress Series 87, 65-76.

Purcell, J.E., 2003. Predation on zooplankton by large jellyfish, Aurelia labiata, Cyanea capillata, and Aequorea aequorea, in Prince William Sound, Alaska. Marine Ecology Progress Series 246, 137-152.

Sullivan, L.J., Costello, J.H., Gifford, D.J., Sullivan, B.K., 2001. Apparent diel feeding by the ctenophore Mnemiopsis leidyi. EOS, Transactions, American Geophysical Union Vol. 82, suppl., [np].

Syväranta, J., Hämäläinen, H., Jones, R.I., 2006. Within-lake variability in carbon and nitrogen stable isotope signatures. Freshwater Biology 51, 1090-1102.

Taylor, L.H., Shellito, S.M., Abello, H.U., Jumars, P.A., 2005. Tidally Phased Emergence Events in a Strongly Tidal Estuary. Estuaries 28, 500-509.

Yahel, R., Yahel, G., Genin, A., 2002. Daily cycles of suspended sand at coral reefs: A biological control. Limnology and Oceanography 47, 1071-1083. 


\section{Figures}

Fig. 1. Temporal variation in average $( \pm \mathrm{SE}) \delta^{13} \mathrm{C}$ values of $C$. mosaicus and its potential diurnal and nocturnal prey in 2005 and potential diurnal, nocturnal and emergent prey in 2006. Dashed lines indicate the maximum and minimum range of average $\delta^{13} \mathrm{C}$ values of C. mosaicus sampled during 2006.

Fig. 2. Distribution of feasible contributions of available sources to C. mosaicus in 2005, derived from IsoSource modelling. $\mathrm{M}=$ median, the ranges are $1 \%$ ile and $99 \%$ ile values.

Fig. 3. Distribution of feasible contributions of available sources to C. mosaicus in 2006, derived from IsoSource modelling. Median and ranges indicated as per Fig. 3.

Fig. 4. Distribution of feasible contributions of available sources to C. mosaicus in 2006, following pooling of emergent copepods and shrimp. Median and ranges indicated as per Fig. 3. 